\title{
Risk analysis of 2-year mortality in elderly male military veterans with non-thyroidal illness syndrome
}

\section{Xinyu Miao}

Chinese PLA General Hospital

Hongzhou Liu

Chinese PLA General Hospital

\section{Xiaomin Fu}

Chinese PLA General Hospital

Huiping Ma

Handan Central Hospital

\section{Xuefeng Chen}

First People's Hospital of Wu'an City

\section{Zhaoyan Gu}

Chinese PLA General Hospital

\section{Banruo Sun}

Chinese PLA General Hospital

Nan Li

Chinese PLA General Hospital

\section{Chunlin Li}

Chinese PLA General Hospital

Shuangtong Yan ( $\square$ ystf@yeah.net)

Chinese PLA General Hospital https://orcid.org/0000-0003-2344-4504

\section{Zhaohui Lyu}

Chinese PLA General Hospital

\section{Research article}

Keywords: NTIS, mortality, old age, inpatients

Posted Date: November 6th, 2020

DOI: https://doi.org/10.21203/rs.3.rs-29177/v2

License: @ (i) This work is licensed under a Creative Commons Attribution 4.0 International License. Read Full License 


\section{Abstract}

Background: Elderly patients with non-thyroidal illness syndrome (NTIS) have relatively severe symptoms and a poor prognosis. However, there are few studies on the correlation between NTIS and mortality among hospitalised elderly patients. This study aimed to investigate the characterization of NTIS inpatients with biochemical indicators and mortality prediction.

Methods: In the present study, 931 male veteran inpatients $\geq 60$ years of age who visited our hospital from January 2012 to December 2013 were selected and divided into the NTIS group $(n=193)$ and normal thyroid

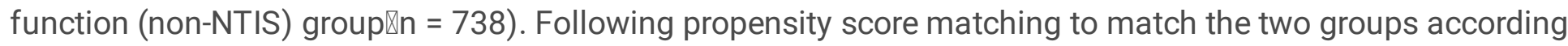
to age and body mass index, the NTIS group and non-NTIS group consisted of 192 and 660 patients, respectively. Data on biochemical indicators and mortality were collected.

Results: Patients had more primary care and more respiratory disease and chronic kidney disease in the NTIS than in the non-NTIS group. Serum total protein (TP), albumin (Alb), prealbumin (PA), haemoglobin (Hb), uric acid (UA), triglyceride (TG), and high-density lipoprotein cholesterol (HDLC) levels were significantly lower, and fasting blood glucose (FBG) and urea nitrogen (UN) levels were higher, in the NTIS than in the non-NTIS group. Triiodothyronine, TP, Alb, and PA levels correlated positively with the $\mathrm{Hb}$ level and negatively with FBG, UN, and creatinine ( $\mathrm{Cr}$ ) levels. The free $\mathrm{T}_{3}$ level correlated positively with TP, Alb, PA, Hb, and UA levels and negatively with FBG, UN, and $\mathrm{Cr}$ levels. A lower free $\mathrm{T}_{3}$ level was associated with increased all-cause mortality after adjusting for covariates. Patients in the NTIS group had a lower survival rate at 6-month (78.65\% vs. $97.73 \%$ ), 1 -year (68.23\% vs. $96.97 \%)$ and 2-year (64.58\% vs. $86.52 \%)$. Receiver operating characteristic curve (ROC) analysis showed that a cut-off free $\mathrm{T}_{3}$ level of $3.45 \mathrm{pmol} / \mathrm{L}$ yielded the highest sensitivity and specificity for predicting all-cause mortality at 2 years.

Conclusion: Among elderly male inpatients, the survival rate was lower in the NTIS group. Serum protein levels and renal function decreased and the FBG level increased with decreasing triiodothyronine and free $T_{3}$ levels. A decreased free $T_{3}$ level in hospitalized elderly male patients was a predictor of poor prognosis.

\section{Background}

Many changes in thyroid hormones occur as a result of illness or nutritional deprivation. These changes consist of decreased levels of serum triiodothyronine $\left(T_{3}\right)$ and/or thyroxine $\left(T_{4}\right)$, without an increase in the thyroid-stimulating hormone (TSH) level, and usually accompanied by elevated reverse $T_{3}\left(\mathrm{rT}_{3}\right)[1,2]$. The combination of these findings is termed non-thyroidal illness syndrome (NTIS), euthyroid sick syndrome, or low $\mathrm{T}_{3}$ syndrome, indicating a systemic disease outside the thyroid that causes abnormal levels of thyroid hormones and is often considered a compensatory mechanism for the body. NTIS has been reported in patients with acute and chronic illnesses, including infectious diseases, cardiovascular and gastrointestinal diseases, cancer, and trauma [3], which are quite common in patients in intensive care units (ICUs) [4, 5]. In previous studies, NTIS showed a high sensitivity and specificity for predicting patient mortality in ICU patients [6]. Serum $\mathrm{T}_{3}$ levels further decrease as the severity of disease progresses. However, among hospitalised elderly patients in the general ward, data on the correlation between NTIS and patient mortality are lacking. 
Elderly patients often have multiple chronic diseases and a poor nutritional status; thus, NTIS is quite common in these patients. Tognini [7] reported that among elderly patients ( $\geq 65$ years of age) hospitalised for acute illness, the prevalence of NTIS was $31.9 \%$ and significantly associated with acute renal failure, New York Heart Association classification IV heart failure, and metastatic cancer. We identified elderly patients who were hospitalised in our hospital. Triiodothyronine, total $T_{4}$, free $T_{3}$, free $T_{4}$, thyrotropin and serum levels of total protein (TP), albumin (Alb), prealbumin (PA), urea nitrogen (UN), creatinine (Cr), uric acid (UA), fasting blood glucose (FBG), blood lipids, alanine transaminase (ALT), aspartate transaminase (AST), and haemoglobin $(\mathrm{Hb})$ were analysed, and 6-month, 1-year and 2-year all-cause mortality rates based on free $T_{3}$ levels was assessed. This study investigated the characterization of NTIS patients with biochemical indicators and mortality prediction that may provide a basis for predicting disease outcome and mortality in hospitalised elderly male patients with NTIS.

\section{Methods}

\section{Patients}

The inclusion criteria for the study were as follows: 1) $\geq 60$ years of age, 2) male, 3) hospitalised between January 2012 and December 2013, and 4) complete data on thyroid function obtained within 1 day of admission. The exclusion criteria were as follows: 1) diagnosed with thyroid disease such as hyperthyroidism, hypothyroidism, subclinical hyperthyroidism, subclinical hypothyroidism, or Hashimoto's thyroiditis, 2) taking amiodarone, euthyroid, glucocorticoid, dopamine, or interferon, and 3) history of thyroid surgery. Because the patients in our hospital are Chinese military veterans, there were few female patients. As such, only male patients were selected as research subjects to reduce the influence of sex bias on the results. Within 2 years, a total of 9,832 patients were admitted to the hospital, 931 of whom were enrolled in the present study. All patients were followed up for 2 years, until December 2015. The subjects were divided based on the presence of NTIS into the NTIS group and normal thyroid function (non-NTIS) group. Because the baseline age and body mass index (BMI) in the two groups differed significantly, the groups were matched by age and weight using the propensity score matching (PSM). After matching, 852 patients were included in the study: 192 in the NTIS group and 660 in the non-NTIS (normal thyroid function) group. At the end of the 2-year follow-up, 157 patients had died and 45 were lost to follow-up (5.28\%). The time and cause of death were recorded for all deceased patients.

\section{Study protocol}

Venous blood samples were collected early in the morning after an overnight fast on the second day after admission. Total $T_{4}$, triiodothyronine, free $T_{3}$, free $T_{4}, T S H, T P, A l b, P A, U N, C r, U A, A L T$, AST, and Hb levels were measured. Radioimmunoassay was used to measure the serum levels of triiodothyronine, free $T_{3}$, total $T_{4}$, free $\mathrm{T}_{4}$, and TSH. The Sysmex Xt-1800 Automated Hematology Analyzer (SYSMEX Corporation, Japan) was used for routine blood tests. Biochemistry measurements were performed using i-CHROMA Reader (Boditech Med Inc. Korea). Normal thyroid hormone levels are as follows: total $\mathrm{T}_{4}(55.34-160.88 \mathrm{nmol} / \mathrm{L})$, triiodothyronine (1.01-2.95 nmol/L), free $\mathrm{T}_{3}(2.76-6.3 \mathrm{pmol} / \mathrm{L})$, free $\mathrm{T}_{4}(10.42-24.32 \mathrm{pmol} / \mathrm{L})$, and TSH (0.35-5.5 ulU/mL). Intra-batch and batch-to-batch variations were $<3.35 \%$ and $<5.04 \%$, respectively. 


\section{Diagnostic criteria for NTIS}

Decreased serum triiodothyronine and/or free $\mathrm{T}_{3}$, normal or mildly reduced total $\mathrm{T}_{4}$ or free $\mathrm{T}_{4}$, and normal TSH levels were the diagnostic criteria for NTIS [8].

\section{Statistical analysis}

PSM (1:4) was used to account for demographic differences in the selected participants. SPSS 22.0 was used for the statistical analysis. Normally distributed data are expressed as means \pm standard deviation ( $x \pm S D$ ) and non-normally distributed data as quartiles. Normally distributed data were compared between the two groups using $t$-test or $t^{\prime}$-test. The rank sum test was used to compare the data distribution between the two groups. All data were evaluated using two-sided tests. Correlations were determined using Pearson correlation analysis for normally distributed data and Spearman's test for non-normally distributed data. Overall survival at 6-month, 1-year and 2-years was estimated using the Kaplan-Meier method. Bivariate and multivariate Cox proportional hazards models were used to evaluate the risk factors associated with patient mortality. Statistical significance was set at $\mathrm{P}<0.05$.

\section{Results}

\section{Comparison of baseline data between the NTIS and non-NTIS groups}

To minimize research bias, PSM was used to match the two groups according to two major factors that influence metabolic indicators and mortality: age and BMI. After matching, statistically significant differences in age and BMI were not observed (see Additional file 1). And after matching by age and BMI, the triiodothyronine, free $T_{3}$, total $T_{4}$ (all $\left.P<0.001\right)$, and TSH levels $(P=0.001)$ were significantly lower in the NTIS group than in the non-NTIS group, moreover, the percentage of patients with primary care was much more in the NTIS group than in the non-NTIS group $(P<0.001)$, and that for patients admitted with respiratory disease and accompanied by respiratory disease and chronic kidney disease were more in the NTIS group than in the non-NTIS group $(P<0.001$, Table 1$)$.

Table 1 Comparison of baseline characteristics between the NTIS and non-NTIS groups ( $\mathrm{x} \pm \mathrm{SD}$ ) 


\begin{tabular}{|c|c|c|c|c|c|}
\hline & $\begin{array}{l}\text { Total } \\
(\mathrm{n}=852)\end{array}$ & $\begin{array}{l}\text { NTIS group } \\
(\mathrm{n}=192)\end{array}$ & $\begin{array}{l}\text { Non-NTIS group } \\
(\mathrm{n}=660)\end{array}$ & $t / Z / c^{2}$ & $\mathrm{P}$ \\
\hline (y) & $87.63 \pm 6.11$ & $87.84 \pm 5.96$ & $87.56 \pm 6.16$ & 0.56 & 0.57 \\
\hline sdothyronine & $1.27 \pm 0.31$ & $0.90 \pm 0.16$ & $1.38 \pm 0.25$ & -25.21 & $<0.001$ \\
\hline $\mathrm{T}_{3}$ & $3.63 \pm 0.83$ & $2.63 \pm 0.54$ & $3.92 \pm 0.66$ & -24.78 & $<0.001$ \\
\hline $\begin{array}{l}\mathrm{O} / \mathrm{L}) \\
\mathrm{ll} \mathrm{T}_{4}\end{array}$ & $86.34 \pm 16.31$ & $75.10 \pm 16.38$ & $89.60 \pm 14.78$ & -11.67 & $<0.001$ \\
\hline $\mathrm{OI} / \mathrm{L})$ & $15.99 \pm 2.73$ & $15.62 \pm 2.99$ & $16.10 \pm 2.63$ & -2.17 & 0.31 \\
\hline i/mL) & $1.88(1.30,2.88)$ & $1.68(1.04,2.74)$ & $1.95(1.36,2.93)$ & -3.37 & 0.001 \\
\hline $\begin{array}{l}\text { sing degree } \\
\text { mary } \\
\text { condary } \\
\text { tertiary }\end{array}$ & $\begin{array}{l}60 \\
792\end{array}$ & $\begin{array}{l}42(21.88 \%) \\
150(78.12 \%)\end{array}$ & $\begin{array}{l}18(2.73 \%) \\
642(97.27 \%)\end{array}$ & 83.30 & $<0.001$ \\
\hline $\begin{array}{l}\text { son for hospit } \\
\text { D } \\
\text { iD } \\
\text { D } \\
\text { hers } \\
\text { lorbidities }\end{array}$ & $\begin{array}{l}\text { al admission } \\
434 \\
282 \\
60 \\
10 \\
66\end{array}$ & $\begin{array}{l}51(26.56 \%) \\
110(57.29 \%) \\
13(6.77 \%) \\
10(5.21 \%) \\
8(4.17 \%)\end{array}$ & $\begin{array}{l}383(58.03 \%) \\
172(26.06 \%) \\
47(7.12 \%) \\
0(0.00 \%) \\
58(8.79 \%)\end{array}$ & 111.24 & $<0.001$ \\
\hline $\begin{array}{l}\text { SD } \\
\text { SD } \\
\text { ID } \\
\text { ID } \\
\text { Imour }\end{array}$ & $\begin{array}{l}282 \\
82 \\
759 \\
112 \\
180 \\
\end{array}$ & $\begin{array}{l}110(57.29 \%) \\
24(12.50 \%) \\
174(90.63 \%) \\
45(23.44 \%) \\
30(15.63 \%) \\
\end{array}$ & $\begin{array}{l}172(26.06 \%) \\
58(8.79 \%) \\
585(88.64 \%) \\
67(10.15 \%) \\
150(22.73 \%)\end{array}$ & $\begin{array}{l}65.51 \\
2.36 \\
0.61 \\
22.99 \\
4.50\end{array}$ & $\begin{array}{l}<0.001 \\
0.13 \\
0.44 \\
<0.001 \\
0.03 \\
\end{array}$ \\
\hline
\end{tabular}

$R D$ respiratory disease, $N S D$ nervous system disease, $C V D$ cardiovascular disease, $C K D$ chronic kidney disease, $T_{3}$ triiodothyronine, $T_{4}$ thyroxine, $T S H$ thyroid-stimulating hormone.

After matching by age and BMI, TP, Alb, PA, Hb, UA, TG, and HDLC levels were significantly lower, while UN and FBG levels were higher, in the NTIS group than in the non-NTIS group (Table 2).

Table 2 Comparison of other baseline biochemical indicators between the NTIS and non-NTIS groups ( $\mathrm{x} \pm \mathrm{SD}$ ) 


\begin{tabular}{|c|c|c|c|c|c|}
\hline & $\begin{array}{l}\text { Total } \\
(\mathrm{n}=852)\end{array}$ & $\begin{array}{l}\text { NTIS group } \\
(\mathrm{n}=192)\end{array}$ & $\begin{array}{l}\text { Non-NTIS group } \\
(\mathrm{n}=660)\end{array}$ & $t / Z$ & $\mathrm{P}$ \\
\hline \multirow{4}{*}{$\begin{array}{l}.) \\
\text {.dd) }\end{array}$} & $66.37 \pm 6.34$ & $64.48 \pm 6.67$ & $66.92 \pm 6.14$ & -4.78 & $<0.001$ \\
\hline & $38.06 \pm 4.57$ & $34.82 \pm 4.43$ & $39.01 \pm 4.17$ & -12.08 & $<0.001$ \\
\hline & $23.19 \pm 7.52$ & $21.86 \pm 9.18$ & $23.58 \pm 6.93$ & -2.79 & 0.005 \\
\hline & $119.10 \pm 18.99$ & $111.46 \pm 18.30$ & $121.32 \pm 18.63$ & -6.48 & $<0.001$ \\
\hline \multirow{3}{*}{$\begin{array}{l}\text { ol/L) } \\
\vdots \\
101 / L)\end{array}$} & $335.25 \pm 100.74$ & $320.34 \pm 120.80$ & $339.58 \pm 93.78$ & -2.34 & 0.02 \\
\hline & $5.88 \pm 1.88$ & $6.68 \pm 2.28$ & $5.65 \pm 1.68$ & 6.83 & $<0.001$ \\
\hline & $3.99 \pm 0.88$ & $4.07 \pm 1.06$ & $3.97 \pm 0.82$ & 1.48 & 0.14 \\
\hline \multirow{4}{*}{$\begin{array}{l}10 \mathrm{l} / \mathrm{L}) \\
\mathrm{iol} / \mathrm{L}) \\
\mathrm{C} C \\
\mathrm{iol} / \mathrm{L}) \\
\mathrm{C} \\
\mathrm{iol} / \mathrm{L})\end{array}$} & $1.20(0.87,1.65)$ & $1.05(0.79,1.65)$ & $1.21(0.90,1.65)$ & -2.09 & 0.04 \\
\hline & $1.19 \pm 0.37$ & $1.13 \pm 0.42$ & $1.20 \pm 0.35$ & -2.37 & 0.02 \\
\hline & $2.30 \pm 0.75$ & $2.34 \pm 0.91$ & $2.28 \pm 0.69$ & 0.94 & 0.35 \\
\hline & $13.00(10.00,20.00)$ & $13.00(9.00,22.00)$ & $13.00(10.00,20.00)$ & -0.54 & 0.59 \\
\hline \multirow{3}{*}{ 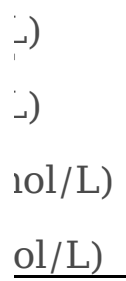 } & $15.00(18.00,23.00)$ & $19.00(14.00,26.83)$ & $18.00(15.00,22.00)$ & -0.90 & 0.37 \\
\hline & $6.40(5.20,8.90)$ & $7.80(5.90,11.30)$ & $6.20(5.10,8.30)$ & -5.95 & $<0.001$ \\
\hline & $82.00(69.00,99.00)$ & $82.00(66.25,121.75)$ & $82.00(70.25,97.00)$ & -1.07 & 0.285 \\
\hline
\end{tabular}

$T P$ total protein, $A l b$ albumin, $P A$ prealbumin, $H b$ haemoglobin, $U A$ uric acid, $F B G$ fasting blood glucose, $T C$ total cholesterol, $T G$ triglyceride, $H D L C$ high-density lipoprotein cholesterol, $L D L C$ lowdensity lipoprotein cholesterol, $A L T$ alanine transaminase, AST aspartate transaminase, $U N$ urea nitrogen, $\mathrm{Cr}$ creatinine

\section{Correlations of triiodothyronine and free $\mathrm{T}_{3}$ levels with important biochemical indicators}

Correlation analysis showed that triiodothyronine was positively correlated with the levels of TP $(r=0.15, P<$ $0.001)$, Alb $(r=0.40, P<0.001), P A(r=0.08, P=0.01)$, and $\mathrm{Hb}(r=0.37, P<0.001)$. Triiodothyronine was negatively correlated with the levels of FBG $(r=-0.28, P<0.001)$, UN $(r=-0.26, P<0.001)$, and $\mathrm{Cr}(r=-0.12$, $P$ $<0.001)$.

Free $T_{3}$ was positively correlated with the levels of TP $(r=0.14, P<0.001)$, Alb $(r=0.50, P<0.001), P A(r=$ $0.19, P<0.001), \mathrm{Hb}(r=0.40, P<0.001)$, and $\mathrm{UA}(r=0.11, P=0.001)$. Free $\mathrm{T}_{3}$ was negatively correlated with the levels of FBG $(r=-0.26, P<0.001)$, UN $(r=-0.20, P<0.001)$, and $\operatorname{Cr}(r=-0.05, P<0.001$; Table 3$)$.

Table 3 Factors associated with triiodothyronine and free $\mathrm{T}_{3}$ 


\begin{tabular}{|c|c|c|c|c|}
\hline & \multicolumn{2}{|c|}{ Triiodothyronine } & \multicolumn{2}{|c|}{ Free $T_{3}$} \\
\hline & $r$ & $\mathrm{P}$ & & $\bar{P}$ \\
\hline $\mathrm{TP}$ & 0.15 & $<0.001$ & 0.14 & $<0.001$ \\
\hline Alb & 0.40 & $<0.001$ & 0.50 & $<0.001$ \\
\hline PA & 0.08 & 0.01 & 0.19 & $<0.001$ \\
\hline $\mathrm{Hb}$ & 0.37 & $<0.001$ & 0.40 & $<0.001$ \\
\hline UA & 0.06 & 0.07 & 0.11 & 0.001 \\
\hline FBG & -0.28 & $<0.001$ & -0.26 & $<0.001$ \\
\hline TC & -0.07 & 0.05 & 0.01 & 0.70 \\
\hline TG & 0.03 & 0.46 & 0.06 & 0.09 \\
\hline HDLC & 0.06 & 0.08 & 0.07 & 0.06 \\
\hline LDLC & 0.00 & 0.93 & 0.06 & 0.11 \\
\hline ALT & 0.04 & 0.25 & 0.04 & 0.21 \\
\hline AST & -0.06 & 0.08 & -0.06 & 0.07 \\
\hline UN & -0.26 & $<0.001$ & -0.20 & $<0.001$ \\
\hline $\mathrm{Cr}$ & -0.12 & $<0.001$ & -0.05 & $<0.001$ \\
\hline
\end{tabular}

$T P$ total protein, $A l b$ albumin, $P A$ prealbumin, $H b$ haemoglobin, $U A$ uric acid, $F B G$ fasting blood glucose, $T C$ total cholesterol, $T G$ triglyceride, $H D L C$ high-density lipoprotein cholesterol, $L D L C$ lowdensity lipoprotein cholesterol, $A L T$ alanine transaminase, $A S T$ aspartate transaminase, $U N$ urea nitrogen, $\mathrm{Cr}$ creatinine

\section{Association of the free $\mathrm{T}_{3}$ level with mortality according to Cox proportional hazards models}

Univariate Cox proportional hazards models showed that the free $T_{3}$ level was associated with reduced patient mortality. Among the other biochemical indicators, Alb and $\mathrm{Hb}$ levels were negatively, whereas FBG, total cholesterol (TC), and ALT levels were positively, correlated with patient mortality. Multivariate models adjusted for other confounding factors showed that a lower free $\mathrm{T}_{3}$ level in elderly male patients is associated with all-cause mortality. Other indicators including Alb and $\mathrm{Hb}$ levels were negatively correlated and the ALT level positively correlated with patient mortality. Patients with respiratory diseases (RD), chronic kidney disease (CKD), and tumours had a higher mortality rate (Table 4). The free $\mathrm{T}_{3}$ level and 2-year mortality rate of all the patients were also determined. According to a receiver operating characteristic (ROC) analysis of the free $T_{3}$ level and 2-year mortality rate, a cut-off free $T_{3}$ level of $3.45 \mathrm{pmol} / \mathrm{L}$ yielded the highest Youden index (0.327), with a sensitivity of 0.675 and specificity of 0.642 (Figure 1).

Table 4. Cox proportional hazards models of the associations of thyroid hormone levels, biochemical indicators, and systemic disease with mortality 


\begin{tabular}{|c|c|c|c|c|c|c|c|c|}
\hline \multirow[t]{2}{*}{ Parameters } & \multirow{2}{*}{\multicolumn{3}{|c|}{ Univariate adjusted }} & \multirow[b]{2}{*}{$P$} & \multirow[b]{2}{*}{$\beta$} & \multicolumn{3}{|c|}{ Multivariate adjusted } \\
\hline & & & & & & HR & & \\
\hline Free $\mathrm{T}_{3}(\mathrm{pmol} / \mathrm{L})$ & -1.30 & 0.27 & $(0.19,0.38)$ & $<0.001$ & -0.66 & 0.52 & $(0.35,0.77)$ & 0.001 \\
\hline & -1.55 & 0.21 & $(0.15,0.29)$ & $<0.001$ & -0.94 & 0.39 & $(0.27,0.56)$ & $<0.001$ \\
\hline $\mathrm{Hb}$ & -1.54 & 0.21 & $(0.16,0.29)$ & $<0.001$ & -0.84 & 0.43 & $(0.30,0.62)$ & $<0.001$ \\
\hline & -0.19 & 0.82 & $(0.53,1.29)$ & 0.40 & -0.06 & 0.95 & $(0.58,1.53)$ & 0.82 \\
\hline FBG $(\mathrm{mmol} / \mathrm{L})$ & 0.62 & 1.86 & $(1.30,2$ & 0.001 & -0.01 & 0.99 & $1.48)$ & 0.96 \\
\hline TC & 0.99 & 2.69 & $(1.63$, & & & 1.26 & 2.36) & 0.46 \\
\hline ALT & 1.12 & 3.07 & $(1.99,4.75)$ & $<0.001$ & 1.18 & 3.26 & $(2.03,5.22)$ & $<0.001$ \\
\hline $\mathrm{RD}$ & 1.16 & 3.20 & $(2.33,4.39)$ & $<0.001$ & 0.42 & 1.52 & $(1.06,2.17)$ & 0.02 \\
\hline NSD & -0.02 & 0.99 & $(0.58,1.68)$ & 0.96 & 0.16 & 1.18 & $(0.68,2.04)$ & 0.56 \\
\hline CVD & 0.42 & 1.52 & $(0.85,2.75)$ & 0.16 & -0.04 & 0.96 & $(0.53,1.75)$ & 0.89 \\
\hline CKD & 1.08 & 2.95 & $(2.07,4.20)$ & $<0.001$ & 1.00 & 2.72 & $(1.91,3.89)$ & $<0.001$ \\
\hline Tumour & 1.04 & 2.82 & $(2.05,3.88)$ & $<0.001$ & 0.97 & 2.63 & $(0.83,3.77)$ & $<0.001$ \\
\hline
\end{tabular}

$T_{3}$ triiodothyronine, $A l b$ albumin, $H b$ haemoglobin, $U A$ uric acid, $F B G$ fasting blood glucose, $T C$ total cholesterol, $A L T$ alanine transaminase, $R D$ respiratory diseases, $N S D$ nervous system disease, $C V D$ cardiovascular disease, $C K D$ chronic kidney disea

Figure 1 Receiver operating characteristic curve assessing the ability of the free triiodothyronine $\left(T_{3}\right)$ level to predict all-cause mortality (free $T_{3}$ cut-off level, 3.445; sensitivity, 67.5\%; specificity, 64.2\%).

\section{Comparison of 6-month, 1-year and 2-year survival rates between the NTIS and non-NTIS groups}

During the 6-month follow-up period, 56 patients died: 41 in the NTIS group and 15 in the non-NTIS group. At 6 months, the survival rate was $78.65 \%$ in the NTIS group and $97.73 \%$ in the non-NTIS group (log-rank c2 = 95.23, $\mathrm{P}<0.001$, Figure 2a). During the 1-year follow-up period, 81 patients died: 61 in the NTIS group and 20 in the non-NTIS group. At 1 year, the survival rate was $68.23 \%$ in the NTIS group and $96.97 \%$ in the non-NTIS group (log-rank $\mathrm{c} 2=158.37, \mathrm{P}<0.001$, Figure $2 \mathrm{~b}$ ). A total of 157 patients died during the 2-year follow-up period; 68 in the NTIS group and 89 in the non-NTIS group. At 2 -years, the survival rate was $64.58 \%$ in the NTIS group and $86.52 \%$ in the non-NTIS group (log-rank c2 $=70.56, P<0.001$, Figure $2 c$ ).

Figure 2 Kaplan-Meier survival curves of the NTIS and non-NTIS groups for the period 6-months (a), 1-year (b) and 2-year (c) after study enrolment.

\section{Discussion}

In the elderly population, thyroid hormone levels can help monitor health status, predict short-term and longterm clinical prognoses, predict disease severity, and assess quality of life and survival status. In previous studies, the frequency of thyroid dysfunction increased with advancing age in the hospitalised elderly patients. The prevalence of NTIS in hospitalised severely or debilitated elderly patients can be as high as $32 \%-62 \%[7,9,10]$. In the present study, among the 931 elderly male patients hospitalised for various reasons, 
there were 193 NTIS patients (20.73\% prevalence rate). After matching by age and BMI, the Alb levels were significantly lower, and the renal function indices and FBG levels higher, in the NTIS group than in the nonNTIS group. In addition, the 2-year survival rate was significantly lower in the NTIS group than in the non-NTIS group. A reduced free $T_{3}$ level was strongly associated with all-cause mortality in NTIS patients, a similar finding of previous studies $[11,12]$.

NTIS is often associated with nutritional deficiencies or acute and chronic diseases. Protein and UA levels are indicators of nutritional status. Proteins also play an important role in the synthesis and transport of thyroid hormones. In several studies, the serum Alb level was reduced, and the free $\mathrm{T}_{3}$ level was positively correlated with the Alb level, in patients with NITS $[13,14]$. In the present study, the Alb levels were also significantly reduced in the NTIS group compared with the non-NTIS group. Correlation analysis showed that TP, Alb, and PA levels decreased as the triiodothyronine and free $T_{3}$ levels decreased. Hypothetically, decreased Alb levels leads to a decrease in the conversion of $T_{4}$ to $T_{3}$, resulting in a decrease in $T_{3}$ levels or a decrease in $T_{4}$ binding to the protein, which accelerates the removal of thyroid hormones $[15,16]$. In the present study, the free $\mathrm{T}_{3}$ level was also positively correlated with the UA and $\mathrm{Hb}$ levels, further confirming that fasting and hunger can cause NTIS [5].

The $T_{4}$ level is strongly associated with CKD. NTIS is a common thyroid dysfunction in CKD patients [13, 17], and its mechanism is associated with the kidney's involvement in the synthesis, secretion, and metabolism of thyroid hormones. In kidney disease, chronic metabolic acidosis and inflammatory factors lead to the inhibition of deiodinase activity, and the conversion of $T_{4}$ to $T_{3}$ in kidney tissue and other tissue types is reduced [18]. Hypothalamic-pituitary-thyroid axis dysfunction [19] combined with loss of $T_{4}$ in the urine causes triiodothyronine and total $\mathrm{T}_{4}$ levels to decrease. A decrease in the glomerular filtration rate (GFR) reduces iodine excretion, resulting in an iodine-blocking effect (Wolff-Chaikoff effect) [19]. Song et al. [20] retrospectively analysed 2,284 subjects with normal TSH levels and found that as the estimated GFR (eGFR) decreased in CKD patients, the prevalence of low $T_{3}$ syndrome gradually increased; the eGFR was positively correlated with the serum $\mathrm{T}_{3}$ level and was independent of age and serum protein levels. In another study, reduced free $\mathrm{T}_{3}$ levels predicted an increased risk of cardiovascular events in CKD patients with proteinuria [21]. In patients with chronic haemodialysis, reduced free $T_{3}$ levels were a strong predictor of all-cause mortality [22]. In the present study, among hospitalised elderly male patients, the UN levels in the NTIS group were higher than in the non-NTIS group. Correlation analysis showed triiodothyronine and free $\mathrm{T}_{3}$ levels were negatively correlated with UN and Cr levels. After adjusting for confounding factors, all-cause mortality was significantly increased in CKD patients.

Compared with young, short-term diabetic patients, the older patients are more likely to develop NTIS. Some studies have compared the thyroid function status of diabetic patients according to age, disease course, and blood glucose control status and found lower free $\mathrm{T}_{3}$ levels in diabetic patients than in normal controls [23, 24]; furthermore, the incidence of cardiovascular events in patients with type 2 diabetes and NTIS was significantly increased [25]. Aging, long diabetes duration, poor blood sugar control, and several complications can increase the prevalence of NTIS, especially in patients with diabetic nephropathy and ketoacidosis [26, 27]. In the present study, triiodothyronine and free $T_{3}$ levels were also negatively correlated with the FBG level. 
In this study, at the end of the 2-year follow-up, a total of 157 patients had died (18.43\% mortality rate). Kaplan-Meier survival analyses showed that the survival rate was significantly lower in the NTIS group $(64.58 \%)$ than in the non-NTIS group (86.52\%). Cox proportional hazards models showed that after removing confounding factors, reduced free $\mathrm{T}_{3}$ levels increased the risk of all-cause death. The ROC analysis showed that when using a free $T_{3}$ cut-off level of $3.45 \mathrm{pmol} / \mathrm{L}$, the Youden index was highest, with a sensitivity of 0.675 and specificity of 0.642 , indicating that when free $T_{3}$ levels are less than $3.45 \mathrm{pmol} / \mathrm{L}$, the risk of death increases. The cut-off level in our study was $3.45 \mathrm{pmol} / \mathrm{L}$ which was near to the low limit of the normal range $(2.76 \mathrm{pmol} / \mathrm{L})$, indicated that for older men with a free $\mathrm{T}_{3}$ level $<3.45 \mathrm{pmol} / \mathrm{L}$ in spite of higher than 2.76 $\mathrm{pmol} / \mathrm{L}$ may also have a poor prognosis and merit close clinical attention, however, it is still need to be further demonstrated by larger studies. In a recent study of 1,190 patients with acute heart failure, the survival rates were significantly lower in patients with low free $\mathrm{T}_{3}$ compared with normal levels, and a multivariate Cox proportional hazards model showed that a low free $\mathrm{T}_{3}$ level was an independent predictor of mortality [28]. Studies on ICU patients and hospitalised chronic patients reported the free $\mathrm{T}_{3}$ level to be an independent predictor of all-cause mortality $[11,29]$. Similar to previous studies, a lower free $\mathrm{T}_{3}$ level in the present study was associated with a worse prognosis in elderly male patients with chronic diseases.

The present study had several limitations including failure to evaluate many factors that affect the patient prognosis. In this retrospective cohort study, thyroid hormone levels were measured at random in patients from different departments according to their doctor's discretion, not according to a standard indication. In addition, although age and BMI were matched between the two groups, the type of care received, treatment plan, treatment timing, severity of the patient's condition, and response to the treatment plan may have affected the patient's condition. Due to the small sample size, many influencing factors were difficult to quantify. The patients were not stratified according to the above-mentioned factors. In addition, only elderly male inpatients were analysed. Whether the above study results can be generalised to the general population requires further research.

\section{Conclusion}

In summary, among elderly male patients hospitalised for multiple causes, the 2-year survival rate was lower in the NTIS group than non-NTIS group. As the triiodothyronine and free $\mathrm{T}_{3}$ levels decreased, the protein levels and renal function worsened, and the FBG level increased. A lower free $T_{3}$ level was associated with an increased risk of all-cause mortality.

\section{Abbreviations}

NTIS: non-thyroidal illness syndrome; ROC: Receiver operating characteristic curves; $T_{3}$ : triiodothyronine; $T_{4}$ : thyroxine; TSH thyroid-stimulating hormone; TP: total protein; Alb: albumin; PA: prealbumin; Hb: haemoglobin, UA: uric acid, TG: triglyceride; HDLC: high-density lipoprotein cholesterol; UN: urea nitrogen; FBG: fasting blood glucose; Cr: creatinine; ICU: intensive care units; ALT: alanine transaminase; AST: aspartate transaminase; BMI: body mass index; PSM: propensity score matching; TC: total cholesterol; RD: respiratory diseases; CKD: chronic kidney disease; NSD: nervous system disease; CVD: cardiovascular disease. 


\section{Declarations}

\section{Acknowledgements}

We thank Meng Wei in the department 3 of orthopedics, Central Hospital of Handan City, Xiaomei Guo in the department of Endoscope Room, First People Hospital of Wu'an City, and Lin Liu in the department of Minimally Invasive Interventional Surgery, First Hospital of Handan City for providing help in data collection.

\section{Authors' contributions}

ST Y conceived, designed and developed the project. XM F, HP M and XF C assisted in data collection. HZ L, $X Y M$ and $Z H L$ conducted data analysis. XY M and $H Z L$ developed the initial drafts of the manuscript. ZY G, $B R S, N L$ and $C L L$ helped in revising subsequent drafts. All authors read and approved the final manuscript.

\section{Funding}

No funding was obtained for this study.

\section{Availability of date and materials}

The datasets used in the analyses described in this study are available from the corresponding author on reasonable request.

\section{Ethics approval and consent to participate}

The study was conducted in accordance with the ethical rules of the Helsinki Declaration. The study protocol was approved by the Ethics Committee of Chinese PLA General Hospital. The permission to access the raw data was granted by the Ethics Committee of Chinese PLA General Hospital.

\section{Consent for publication}

Not applicable.

\section{Competing interests}

The authors declare that they have no competing interests.

\section{Author details}

${ }^{1}$ Department of Endocrinology, The Second Medical Center \& National Clinical Research Center for Geriatric Diseases, Chinese PLA General Hospital, Beijing 100853, China

${ }^{2}$ Department 2 of Pediatrics, Central Hospital of Handan City, Handan, Hebei province 056001, China

${ }^{3}$ Department of Endocrinology, First People Hospital of Wu'an City, Wu'an, Hebei province 056300, China

${ }^{4}$ Department of Endocrinology, The First Medical Center, Chinese PLA General Hospital, Beijing 100853, China 


\section{References}

1. de Vries EM, Fliers E, Boelen A. The molecular basis of the non-thyroidal illness syndrome. J Endocrinol 2015; 225(3):R67-81.

2. Farwell AP. Nonthyroidal illness syndrome. Curr Opin Endocrinol Diabetes Obes 2013; 20(5):478-84.

3. Wang B, Liu S, Li L, Yao Q, Song R, Shao X et al. Non-thyroidal illness syndrome in patients with cardiovascular diseases: A systematic review and meta-analysis. Int J Cardiol 2017; 226:1-10.

4. Fliers E, Bianco AC, Langouche L, Boelen A. Thyroid function in critically ill patients. Lancet Diabetes Endocrinol 2015; 3(10):816-25.

5. Van den Berghe G. Non-thyroidal illness in the ICU: a syndrome with different faces. Thyroid 2014; 24(10):1456-65.

6. Wang YF, Heng JF, Yan J, Dong L. Relationship between disease severity and thyroid function in Chinese patients with euthyroid sick syndrome. Medicine (Baltimore) 2018; 97(31):e11756.

7. Tognini S, Marchini F, Dardano A, Polini A, Ferdeghini M, Castiglioni M et al. Non-thyroidal illness syndrome and short-term survival in a hospitalised older population. Age Ageing 2010; 39(1):46-50.

8. K H, M S, K S, E A. Reed larsen williams textbook of endocrinolgy, 11 edn: Canada:Saunders Elsevier; 2008.

9. Iglesias P, Munoz A, Prado F, Guerrero MT, Macias MC, Ridruejo E et al. Alterations in thyroid function tests in aged hospitalized patients: prevalence, aetiology and clinical outcome. Clin Endocrinol (Oxf) 2009; 70(6):961-7.

10. Bossoni S, Cossi S, Marengoni A, De Martinis M, Calabrese P, Leonardi R et al. Low T3 syndrome and outcome in elderly hospitalized geriatric patients. J Endocrinol Invest 2002; 25(10 Suppl):73-4.

11. Ataoglu HE, Ahbab S, Serez MK, Yamak M, Kayas D, Canbaz ET et al. Prognostic significance of high free T4 and low free T3 levels in non-thyroidal illness syndrome. Eur J Intern Med 2018; 57:91-5.

12. Sato Y, Yoshihisa A, Kimishima Y, Kiko T, Kanno Y, Yokokawa T et al. Low T3 Syndrome Is Associated With High Mortality in Hospitalized Patients With Heart Failure. J Card Fail 2019; 25(3):195-203.

13. Pan B, Du X, Zhang H, Hua X, Wan X, Cao C. Relationships of Chronic Kidney Disease and Thyroid Dysfunction in Non-Dialysis Patients: A Pilot Study. Kidney Blood Press Res 2019; 44(2):170-8.

14. Chavez Valencia V, Mejia Rodriguez O, Viveros Sandoval ME, Abraham Bermudez J, Gutierrez Castellanos $\mathrm{S}$, Orizaga de la Cruz $\mathrm{C}$ et al. Prevalence of malnutrition-inflammation complex syndrome and its correlation with thyroid hormones in chronic haemodialysis patients. Nefrologia 2018; 38(1):57-63.

15. Flier JS, Harris M, Hollenberg AN. Leptin, nutrition, and the thyroid: the why, the wherefore, and the wiring. J Clin Invest 2000; 105(7):859-61.

16. De Groot LJ. Dangerous dogmas in medicine: the nonthyroidal illness syndrome. J Clin Endocrinol Metab 1999; 84(1):151-64.

17. Iglesias P, Bajo MA, Selgas R, Diez JJ. Thyroid dysfunction and kidney disease: An update. Rev Endocr Metab Disord 2017; 18(1):131-44.

18. Zoccali C, Tripepi G, Cutrupi S, Pizzini P, Mallamaci F. Low triiodothyronine: a new facet of inflammation in end-stage renal disease. J Am Soc Nephrol 2005; 16(9):2789-95. 
19. Basu G, Mohapatra A. Interactions between thyroid disorders and kidney disease. Indian J Endocrinol Metab 2012; 16(2):204-13.

20. Song SH, Kwak IS, Lee DW, Kang YH, Seong EY, Park JS. The prevalence of low triiodothyronine according to the stage of chronic kidney disease in subjects with a normal thyroid-stimulating hormone. Nephrol Dial Transplant 2009; 24(5):1534-8.

21. Yang JW, Han ST, Song SH, Kim MK, Kim JS, Choi SO et al. Serum T3 level can predict cardiovascular events and all-cause mortality rates in CKD patients with proteinuria. Ren Fail 2012; 34(3):364-72.

22. Fragidis S, Sombolos K, Thodis E, Panagoutsos S, Mourvati E, Pikilidou M et al. Low T3 syndrome and long-term mortality in chronic hemodialysis patients. World J Nephrol 2015; 4(3):415-22.

23. Custro N, Scafidi V, Borsellino T. [Changes in the thyroid hormone picture that may be found in severely decompensated type II diabetics]. Minerva Med 1991; 82(1-2):9-14.

24. Kabadi UM, Premachandra BN. Low triiodothyronine and raised reverse triiodothyronine levels in patients over fifty years of age who have type II diabetes mellitus: influence of metabolic control, not age. J Am Geriatr Soc 1984; 32(5):375-9.

25. Moura Neto A, Parisi MC, Tambascia MA, Pavin EJ, Alegre SM, Zantut-Wittmann DE. Relationship of thyroid hormone levels and cardiovascular events in patients with type 2 diabetes. Endocrine 2014; 45(1):84-91.

26. Zhao W, Li X, Liu X, Lu L, Gao Z. Thyroid Function in Patients with Type 2 Diabetes Mellitus and Diabetic Nephropathy: A Single Center Study. J Thyroid Res 2018; 2018:9507028.

27. Mirboluk AA, Rohani F, Asadi R, Eslamian MR. Thyroid function test in diabetic ketoacidosis. Diabetes Metab Syndr 2017; 11 Suppl 2:S623-s5.

28. Asai K, Shirakabe A, Kiuchi K, Kobayashi N, Okazaki H, Matsushita M et al. Relation of Low Triiodothyronine Syndrome Associated With Aging and Malnutrition to Adverse Outcome in Patients With Acute Heart Failure. Am J Cardiol 2020; 125(3):427-35.

29. Wang F, Pan W, Wang H, Wang S, Pan S, Ge J. Relationship between thyroid function and ICU mortality: a prospective observation study. Crit Care 2012; 16(1):R11.

\section{Supplementary Table}

Additional file 1 Baseline patient characteristics before and after PSM

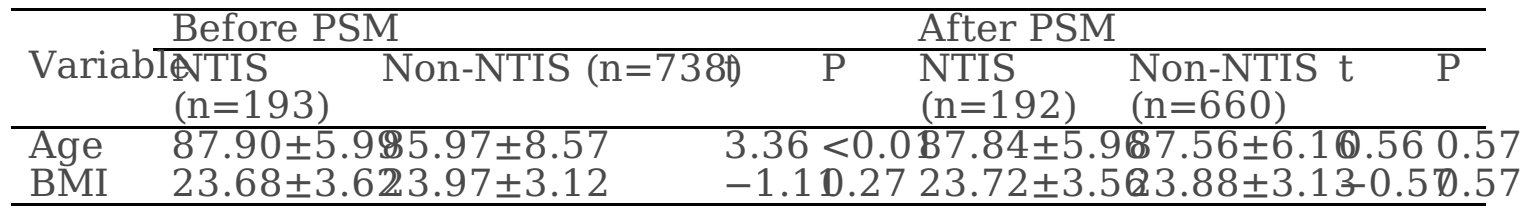

PSM propensity score matching, NTIS non-thyroidal illness syndrome, $B M I$ body mass index

\section{Figures}




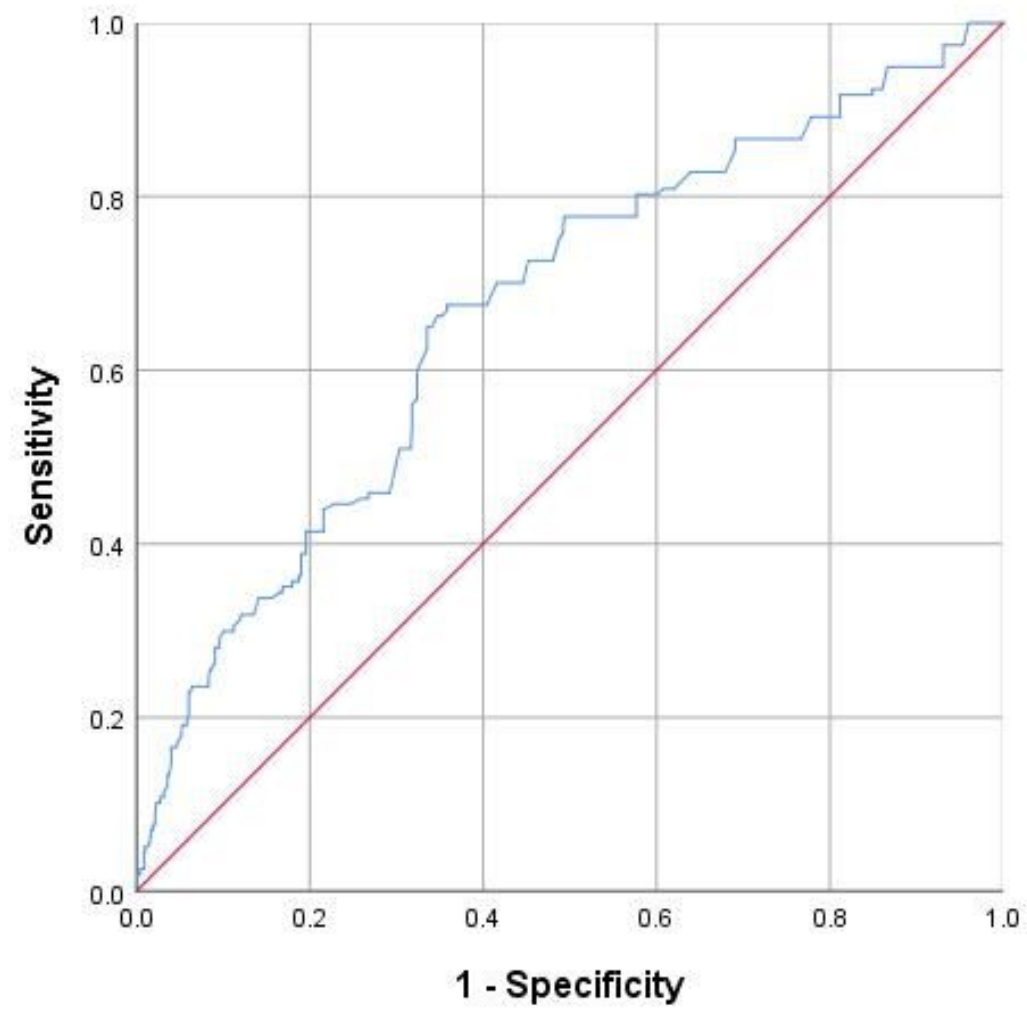

Figure 1

Receiver operating characteristic curve assessing the ability of the free triiodothyronine (T3) level to predict all-cause mortality (free T3 cut-off level, 3.445; sensitivity, 67.5\%; specificity, 64.2\%). 


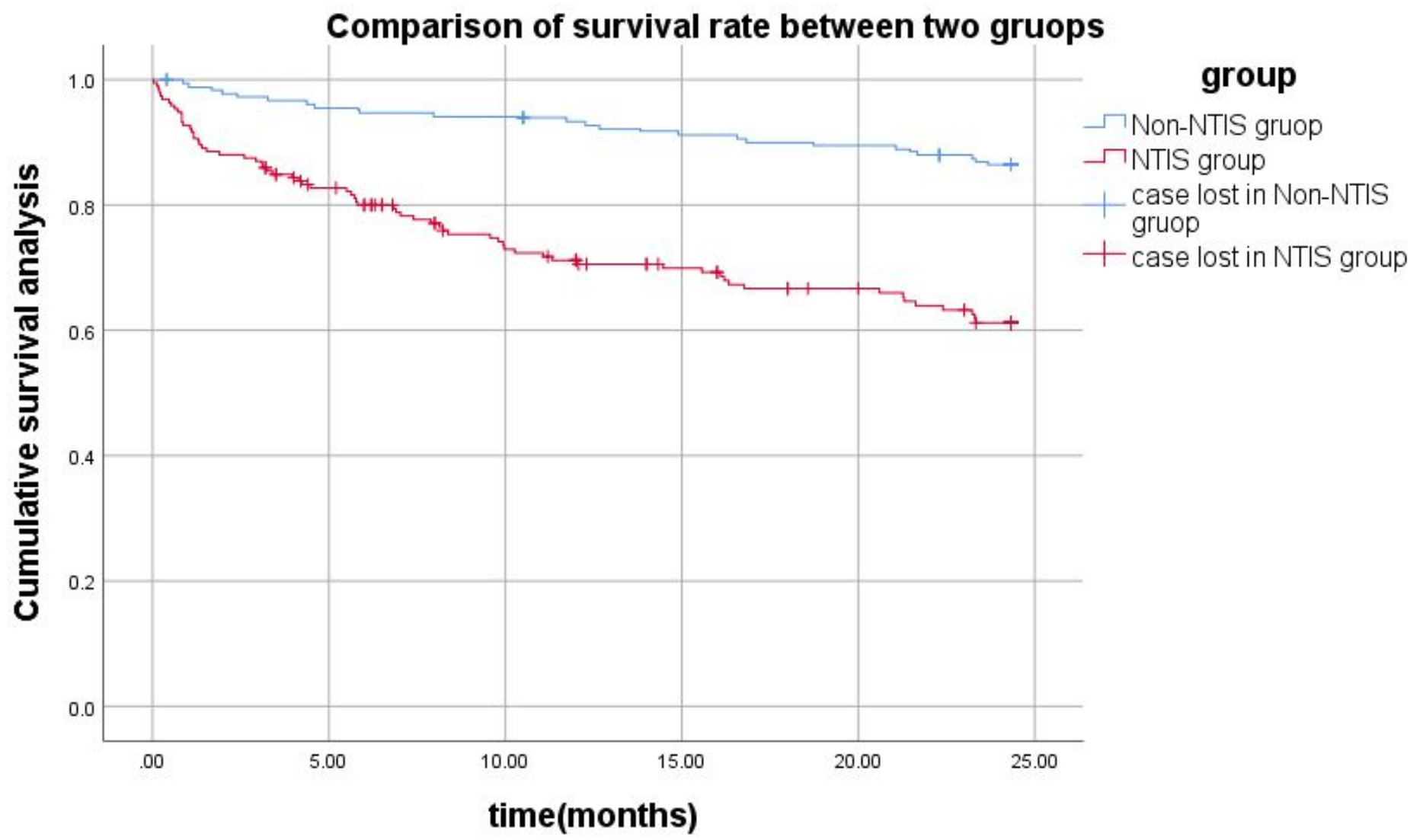

Figure 2

Kaplan-Meier survival curves of the NTIS and non-NTIS groups over 24 months. 